\title{
Análise de $\beta$-ecdisona em plantas in vivo e in vitro de Pfaffia glomerata (Spreng.) Pedersen, através da Cromatografia em Camada Delgada
}

\author{
FLORES, R. ${ }^{1 *}$; CEZAROTTO, V. ${ }^{2}$; BRONDANI, D. ${ }^{2}$; GIACOMELLI, S.R. ${ }^{2}$; NICOLOSO, F.T. ${ }^{1}$ \\ Laboratório de Biotecnologia Vegetal, Centro de Ciências Naturais e Exatas (CCNE), Universidade Federal de \\ Santa Maria (UFSM), Avenida Roraima, 1000, Cidade Universitária, Bairro Camobi, CEP: 97105-900, Santa Maria- \\ Brasil. ‘rejane.flores@terra.com.br, ftnicoloso@yahoo.com ${ }^{2}$ Laboratório de Análises Químicas e Farmacêuticas \\ (LAQUIFAR), Universidade Regional Integrada (URI), CEP: 98400-000, Rua Assis Brasil, 709, Frederico Westphalen- \\ Brasil. laquifar@fw.uri.br
}

\begin{abstract}
RESUMO: Pfaffia glomerata (Spreng.) Pedersen, conhecida como ginseng brasileiro, é uma planta extensivamente usada na medicina popular em decorrência de possuir propriedades fitoterápicas. $O$ objetivo deste trabalho foi verificar a presença de $\beta$-ecdisona nas raízes e partes aéreas de plantas in vivo e in vitro provenientes de dois acessos (BRA e JB-UFSM) de Pfaffia glomerata através da cromatografia em camada delgada (CCD). Nas plantas in vivo, as manchas cromatográficas demonstraram que a $\beta$-ecdisona está presente na raiz e na parte aérea. Os acessos não apresentaram diferenças em relação ao perfil de manchas cromatográficas. A análise em CCD não detectou a presença de $\beta$-ecdisona nas plantas cultivadas in vitro.
\end{abstract}

Palavras-chave: ginseng brasileiro, CCD, ecdisteróides, controle de qualidade, cultivo in vitro

\begin{abstract}
Analysis of $\beta$-ecdysone from in vivo and in vitro cultured plants of Pfaffia glomerata (Spreng.) Pedersen using Thin-Layer Chromatography. Pfaffia glomerata (Spreng.) Pedersen, known as Brazilian ginseng, is a plant extensively used in folk medicine due to its phytotherapic characteristics. The aim of this study was to evaluate the presence of $\beta$-ecdysone in the roots and shoots of in vivo and in vitro cultured plants of two sources (BRA and JB-UFSM) of Pfaffia glomerata using Thin-Layer Chromatography (TLC). For in vivo cultured plants, TLC plates showed that $\beta$-ecdysone was present in the roots and shoots. Sources showed no differences concerning TLC plates. TLC analysis did not detect $\beta$-ecdysone in the in vitro cultured plants.
\end{abstract}

Key words: Brazilian ginseng, TLC, ecdysteroids, quality control, in vitro culture

\section{INTRODUÇÃO}

Várias indústrias farmacêuticas brasileiras produzem fitoterápicos e suplementos alimentares contendo em sua formulação raízes de Pfaffia glomerata (Spreng.) Pedersen (Brasil, 2004). Esta espécie, conhecida popularmente como ginseng brasileiro, apresenta várias propriedades medicinais, destacando-se os efeitos antidepressivos, tônicos e afrodisíacos, além de ser utilizada para o tratamento de diabetes, reumatismo, esgotamento físico e mental, falta de memória e estresse (Magalhães, 2000; Zimmer et al., 2006). Vários compostos foram isolados e identificados a partir das raízes de $P$. glomerata, como o ácido glomérico, ácido oleanólico, ácido famérico, além de vários ecdisteróides (Shiobara et al., 1993). Nos dias atuais, o ecdisteróide $\beta$ - ecdisona é utilizado como marcador químico no controle de qualidade da matéria-prima e dos medicamentos produzidos com $P$. glomerata (Magalhães, 2000; Zimmer et al., 2006).

Em função dos critérios de eficácia, segurança e qualidade exigida para a obtenção do registro de medicamentos fitoterápicos no Ministério da Saúde (Brasil, 2004), diversos ensaios farmacológicos foram conduzidos com P. glomerata, tendo em vista o desenvolvimento e a validação de técnicas necessárias para o controle da qualidade da matéria-prima (Zimmer et al., 2006).

A cromatografia em camada delgada (CCD) é uma das técnicas mais empregadas no controle da qualidade de plantas medicinais devido à

Recebido para publicação em 07/08/2008

Aceito para publicação em 09/03/2009 
simplicidade, rapidez, praticidade e baixo custo; a grande variedade de combinações entre fases móveis e estacionárias torna a CCD uma técnica extremamente versátil e de grande aplicação (Gil et al., 2005).

Em P. glomerata, a obtenção de perfil cromatográfico de amostras de raízes mostra-se ferramenta valiosa para a identificação, quantificação e avaliação da estabilidade da matéria-prima e ou extratos derivados. Recentemente, Vigo et al. (2004) salientaram a importância da CCD para a padronização farmacognóstica e correta identificação de P. glomerata, possibilitando o controle de qualidade.

Apesar de, nos dias atuais, o metabólito $\beta$ ecdisona ser utilizado como produto de referência no controle de qualidade das raízes de $P$. glomerata, há poucas pesquisas referentes à presença deste composto em outros órgãos da planta, tampouco em relação à presença do mesmo em plantas in vitro. Estes estudos fornecerão novas informações à indústria farmacêutica, além de contribuir para um melhor entendimento do papel fisiológico dos ecdisteróides nas plantas. Neste contexto, o objetivo deste estudo foi verificar a presença de $\beta$-ecdisona nas raízes e partes aéreas de plantas in vivo e in vitro, oriundas de dois acessos de P. glomerata, através da cromatografia em camada delgada.

\section{MATERIAL E MÉTODO}

Utilizaram-se dois acessos (BRA e JB-UFSM) de $P$. glomerata (Spreng.) Pedersen, sendo o acesso BRA coletado no município de Querência do Norte, PR e o acesso JB-UFSM coletado no Jardim Botânico da UFSM, Santa Maria, RS. Uma exsicata desta espécie encontra-se depositada no Herbário do Departamento de Biologia da UFSM (SMDB 7606).

Segmentos nodais $(1 \mathrm{~cm})$ de ambos os acessos foram desinfestados e cultivados em meio MS (Murashige \& Skoog, 1962), suplementado com sacarose $\left(30 \mathrm{~g} \mathrm{~L}^{-1}\right)$, mio-inositol (100 $\left.\mathrm{mg} \mathrm{L}^{-1}\right)$ e ágar $\left(6 \mathrm{~g} \mathrm{~L}^{-1}\right)$ (Nicoloso et al., 2001). $\mathrm{O} \mathrm{pH}$ foi ajustado para 5,9. As plantas foram cultivadas em sala de crescimento com temperatura de $25 \pm 2^{\circ} \mathrm{C}, 16$ horas de fotoperíodo e $35 \mathrm{mM} \mathrm{m}^{-2} \mathrm{~s}^{-1}$ de luminosidade. Após 30 dias de cultivo, as plantas foram aclimatizadas e transferidas para condições de cultivo em solo, no município de São Pedro do Sul, RS, Brasil.

A presença da $\beta$-ecdisona (Figura 1) foi analisada nas raízes e partes aéreas das plantas in vitro (30 dias de idade), bem como, nas plantas transferidas para o campo (in vivo), as quais foram coletadas, durante a primavera, dois anos após o plantio no solo. O material vegetal foi seco em estufa a $50^{\circ} \mathrm{C}$ (Simões et al., 2001) e triturado em gral. As amostras $(200 \mathrm{mg})$ foram extraídas com metanol (2 vezes, $5 \mathrm{~mL}$ ) em banho ultra-sônico, durante 20

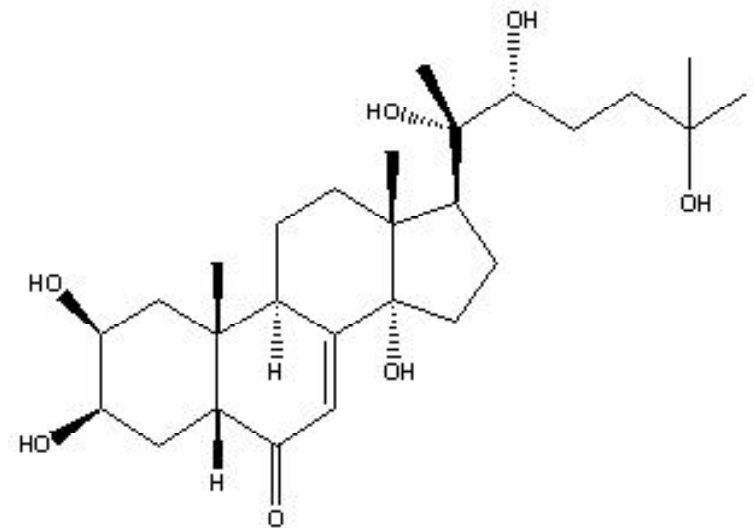

FIGURA 1. Estrutura do fitoecdisteróide $\beta$-ecdisona.

minutos. O sobrenadante foi removido após centrifugação a $1000 \mathrm{~g}$ durante 10 minutos e os extratos obtidos das duas extrações foram combinados (10 mL) (Flores, 2006).

Foram aplicados $15 \mathrm{~L}$ das amostras e do padrão da $\beta$-ecdisona, com auxílio de capilar graduado, em cromatofolhas de alumínio (AL TLC Silicagel $60 \mathrm{~F}_{254}$ Merck, $20 \times 20 \mathrm{~cm}$ ). O sistema foi mantido em câmara de saturação com os eluentes: n-butanol, acetato de etila, ácido fórmico e água (4:1:0,6:0,5). A visualização das manchas foi efetuada por exposição à luz UV a $254 \mathrm{~nm}$ e a revelação com vanilina sulfúrica, em capela, com posterior aquecimento em estufa até o aparecimento de cores na placa. O método cromatográfico utilizado seguiu a metodologia proposta por Vigo et al. (2004) para esta espécie.

As placas foram confeccionadas em triplicata e documentadas por fotografia digital. A presença de $\beta$-ecdisona na placa cromatográfica foi realizada pela comparação dos Fatores de Retenção (Rfs) das manchas das amostras com o do padrão $\beta$-ecdisona adquirido da ChromaDex Inc. (Califórnia, U.S.A.). A solução de $\beta$-ecdisona foi preparada em metanol a $25 \mathrm{mg} \mathrm{mL}^{-1}$. Realizou-se a co-cromatografia para confirmar a identificação da $\beta$-ecdisona.

\section{RESULTADO E DISCUSSÃO}

As análises cromatográficas das amostras das plantas in vivo dos acessos de $P$. glomerata (Spreng) Pedersen mostraram a presença de $\beta$ ecdisona tanto nas raízes como na parte aérea das plantas. A mancha correspondente à $\beta$-ecdisona apresentou $\mathrm{Rf}=0,7$ e coloração esverdeada, o que a diferenciou das demais manchas observadas na placa cromatográfica.

Recentemente, devido à importância das raízes do ginseng brasileiro para a fabricação de fitoterápicos, a presença e o doseamento de $\beta$ ecdisona vêm sendo muito estudados (Flores, 2006), 
porém as pesquisas estão limitadas ao sistema radicular da planta (Magalhães, 2000; Vigo et al., 2004). Contudo, os resultados obtidos neste estudo mostraram que a parte aérea de $P$. glomerata também contém $\beta$-ecdisona, além de vários outros metabólitos, cujas manchas não foram detectadas nas raízes (Figuras 2A, 1B, 1E e 1F). De fato, várias pesquisas vêm demonstrando que os fitoecdisteróides podem ser biossintetizados e/ou acumulados em diferentes órgãos das plantas. Em Pfaffia iresinoides, estudos sobre o teor órgão-específico de ecdisteróides mostraram que a $\beta$-ecdisona estava presente tanto nas raízes como no caule e folhas desta espécie (Nishimoto et al., 1987), o que concorda com os resultados obtidos neste estudo.

Por outro lado, manchas correspondentes à $\beta$-ecdisona não foram detectadas nos extratos metanólicos das raízes e partes aéreas das plantas in vitro, em ambos os acessos estudados (Figuras 2C, 1D, 1G e 1H). Apesar de estas amostras apresentarem manchas com $\mathrm{Rf}$ muito similar àquele do padrão de $\beta$-ecdisona (Figura 2P), a cocromatografia mostrou que as manchas detectadas nas plantas in vitro não se tratavam da $\beta$-ecdisona, pois aquelas apresentavam coloração diferente quando comparada à mancha da $\beta$-ecdisona. Ao contrário, estudos conduzidos com plantas in vitro Ajuga evidenciaram um alto teor de fitoecdisteróides (Tomás et al., 1993). Contudo, é importante salientar que é muito difícil comparar a produção de determinado metabólito produzido a partir de células e/ou tecidos in vitro, com aqueles produzidos nos tecidos de plantas completas, cultivadas a campo. Neste estudo, a não detecção da $\beta$-ecdisona nas plantas in vitro pode ser devido a pouca diferenciação dos tecidos e órgãos, além do reduzido tempo de cultivo in vitro (30 dias), quando comparado às plantas cultivadas a campo, as quais apresentavam dois anos de idade. Adiferenciação dos tecidos, a idade da planta e as condições do meio ambiente são importantes fatores que afetam a produção de metabólitos secundários.

Constatou-se que os perfis cromatográficos das amostras in vivo e in vitro do acesso JB-UFSM (Figuras 2A, 1B, 1C, 1D) foram similares as do acesso BRA (Figuras 2E, 1F, 1G, 1H). Estes resultados demonstram que, apesar da $P$. glomerata apresentar grande variabilidade genética e morfológica (Magalhães, 2000), os acessos estudados neste trabalho não apresentaram diferenças marcantes em relação à composição química. O padrão geral das manchas, bem como o Rf e a coloração da mancha correspondente à $\beta$-ecdisona obtidos neste estudo, com as plantas in vivo, foram similares aos encontrados por Vigo et al. (2004), em amostras de raízes de $P$. glomerata.

Apesar de a $\beta$-ecdisona não ter sido detectada nas amostras in vitro, a comparação dos perfis cromatográficos das partes aéreas das plantas in vivo e in vitro, mostrou que as últimas apresentam um maior número de manchas (Figuras 2D, 2H) quando comparado às plantas coletadas a campo (in vivo) (Figuras 2B, 2F). Várias pesquisas têm mostrado que as condições impostas durante o cultivo in vitro podem influenciar na biossíntese e/ou acúmulo de diferentes metabólitos, inclusive de ecdisteróides (Tomás et al., 1993).

O sistema cromatográfico adotado neste estudo mostrou-se como uma alternativa viável para a detecção rápida de â-ecdisona em amostras de

\section{Acesso JB-UFSM}

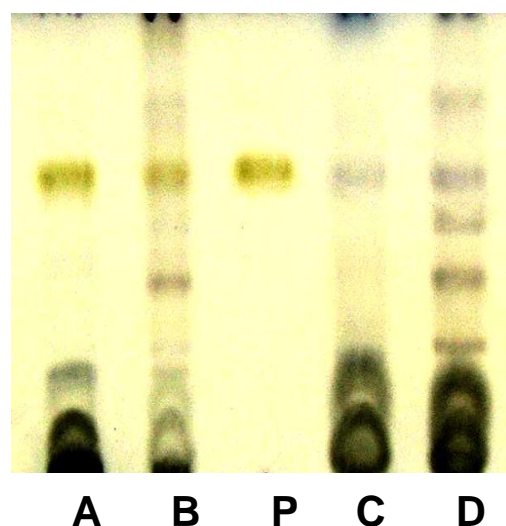

\section{Acesso BRA}

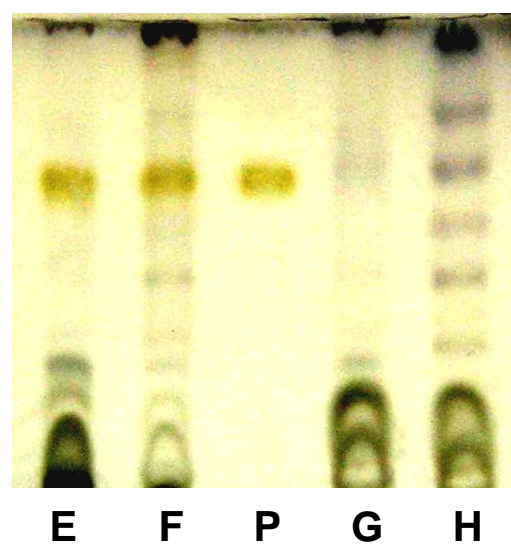

FIGURA 2. Comparação cromatográfica dos extratos metanólicos das raízes e partes aéreas de plantas in vivoe in vitro de dois acessos de Pfaffia glomerata. A) raízes do acesso JB-UFSM in vivo, B) parte aérea do acesso JBUFSM in vivo, C) raízes do acesso JB-UFSM in vitro, D) parte aérea do acesso JB-UFSM in vitro, $\mathbf{E}$ ) raízes do acesso BRA in vivo, $\mathbf{F}$ ) parte aérea do acesso BRA in vivo, $\mathbf{G}$ ) raízes do acesso BRA in vitro, $\mathbf{H}$ ) parte aérea do acesso BRA in vitro, P) padrão $\beta$-ecdisona. 
ginseng brasileiro. A obtenção de um perfil cromatográfico de amostras de raízes de diferentes acessos de $P$. glomerata mostra-se útil para o controle da qualidade da matéria-prima, principalmente na avaliação da estabilidade das drogas ou extratos derivados. Além disso, Vigo et al. (2004) ressaltaram a importância da CCD na avaliação da pureza e da autenticidade de diferentes drogas comercializadas como sendo provenientes de raízes $P$. glomerata.

Apesar de a CCD ser uma ferramenta muito útil para a identificação rápida de compostos de interesse em uma amostra, neste estudo, esta técnica mostrou-se pouco sensível para a análise de $\beta$-ecdisona em amostras de plantas cultivadas in vitro. A metodologia de CCD adotada mostrou-se adequada apenas para a detecção de $\beta$-ecdisona quando em concentração igual ou superior a $25 \mathrm{mg} \mathrm{mL}^{-1}$. Desta forma, a não visualização da mancha referente à $\beta$ ecdisona nas plantas in vitro pode ser devido a ausência do composto no material, pela presença da Aperfeiçoamento de Pessoal de Nível Superior (CAPES) pelo auxílio financeiro e a Embrapa Recursos Genéticos e Biotecnologia (Brasília, DF, Brasil) pelo fornecimento do acesso BRA de Pfaffia glomerata.

\section{CONCLUSÃO}

Os resultados permitiram concluir que: a) a CCD é técnica viável para a detecção de $\beta$-ecdisona nas raízes e partes aéreas de plantas in vivo de $P$. glomerata; b) os acessos BRA e JB-UFSM não apresentam diferenças marcantes em relação ao perfil de bandas cromatográficas e c) a análise em CCD não detecta $\beta$-ecdisona em plantas in vitro.

\section{AGRADECIMENTO}

Os autores agradecem à Coordenação de Aperfeiçoamento de Pessoal de Nível Superior (CAPES) pelo auxílio financeiro e a Embrapa Recursos Genéticos e Biotecnologia (Brasília, DF, Brasil) pelo fornecimento do acesso BRA de Pfaffia glomerata.

\section{REFERÊNCIA}

BRASIL. Ministério da Saúde. Agência Nacional de Vigilância Sanitária (ANVISA). Resolução RDC no 48 de 16 de março de 2004. Dispõe sobre o registro de medicamentos fitoterápicos. 2004. Diário Oficial da União, Brasília, DF, 18 mar. 2004.

FLORES, R. Cultura de tecidos e produção de becdisona em Pfaffia glomerata (Spreng.) Pedersen e Pfaffia tuberosa (Spreng.) Hicken. 2006. 168p. Tese (Doutorado - Área de Concentração em Produção Vegetal) - Centro de Ciências Rurais, Universidade Federal de Santa Maria, Santa Maria.

GIL, E.S. et al. Controle físico-químico de qualidade de medicamentos. Campo Grande: UNIDERP, 2005. 438p. MAGALHÃES, P.M. Agrotecnologia para el cultivos de fafia e ginseng brasileiro. In: MARTINEZ, J.V. et al. Fundamentos de agrotecnologia de cultivo de plantas medicinales iberoamericanas. Bogotá: CYTED, 2000. p.323-32.

MURASHIGUE, T.; SKOOG, F. A revised medium for rapid growth and bioassays with tabacco tissue cultures. Physiologia Plantarum, v.5, p.473-97, 1962.

NICOLOSO, F.T. et al. Micropropagação do Ginseng brasileiro [Pfaffia glomerata (Spreng.) Pedersen]. Revista Brasileira de Plantas Medicinais, v.3, p.11-8, 2001. NISHIMOTO, N. et al. Ecdysteroids from Pfaffia iresinoides and reassignment of some ${ }^{13} \mathrm{CNMR}$ chemical shifts. Phytochemistry, v.26, n.9, p.2505-7, 1987.

SHIOBARA, Y. et al. A nortriterpenoid, triterpenoid and ecdysteroids from Pfaffia glomerata. Phytochemistry, v.32, p.1527-30, 1993.

SIMÕES, C.M.O. et al. Farmacognosia: da planta ao medicamento. 3.ed. Porto Alegre/Florianópolis: UFRGS/ UFSC, 2001. 833p.

TOMÁS, J. et al. Phytoecdisteroid production by Ajuga reptans tissue culture. Phytochemistry, v.32, n.2, p.31724, 1993.

VIGO, C.L.S. et al. Caracterização farmacognóstica comparativa de Pfaffia glomerata (Spreng.) Pedersen e Hebanthe paniculata Martius - Amaranthaceae Kuntze. Revista Brasileira de Plantas Medicinais, v.6, n.2, p.719, 2004.

ZIMMER, A.R. et al. HPLC method for the determination of ecdysterone in extractive solution from Pfaffia glomerata. Journal of Pharmaceutical and Biomedical Analysis, v.40, n.2, p.450-3, 2006. 